\title{
Education Matters
}

\section{Nursing Now: nurses at the heart of the challenge to improve global health}

Nurses are now at the heart of the dedicated challenge to improve global health. It is anticipated that by developing nursing, a direct contribution will be made to address three of the United Nation's Sustainable Development Goals of improving health, promoting gender equality and strengthening economies, the triple impact (APPG 2016). The Triple Impact report published in 2016 by a group of UK parliamentarians, led by Lord Nigel Crisp concluded that realising the global health goals will not be achieved without strengthening the profile and status of nursing and by harnessing their collective energies and desires to do more. The report was so well received that it led to the Nursing Now campaign being created with support from key international organisations such as the International Council of Nurses, the Royal College of Nursing and the Commonwealth Nurses and Midwives Federation, with full support from the Director-General of the World Health Organisation, Dr Tedros Adhanom. Nursing Now was launched in London on $27^{\text {th }}$ February 2018 and is due to run until the end of 2020 , the $200^{\text {th }}$ anniversary of the birth of Florence Nightingale and a time when nurses will be celebrated across the world (ICN 2018).

It is well known that nurses make up the largest healthcare workforce globally, yet, there continues to be a shortage of 9 million nurses and midwives worldwide. Nursing Now hopes to make a significant contribution to reducing this figure by 2030 . Never before has there been such a focus on nurses around the world by so many powerful organisations in an attempt to recognise their contribution to improving global health. Importantly, funding is being released to help nurses worldwide to access education and training, as well as help them to share research and evidence of good practice. The $21^{\text {st }}$ Century requires a number of changes to the way nurses work. There is a continued need for new and innovative services, care that is person-centred and a greater focus on prevention and the use of technology. Maximising nurses' contribution means that they should be working to the extent of their education ability (IoM 2010), be valued for the work that they do, and encouraged to engage in policy and decision-making. Being a female dominated profession, nurses need to develop a confidence in their capability; they need to be educated to embrace a greater awareness of what is happening around them and be more politically astute (Rosser 2017).

So, what will this mean for nurses in the UK?

From student nurses to advanced practitioners, the emphasis on raising the profile and status of nurses around the world should encourage them to feel empowered to make a difference to people's lives, to influence policymakers and be supported to lead, learn and build a global movement (ICN 2018). As a nurse educator, we have an opportunity to embrace this campaign and support our students who will become the healthcare leaders of the future, to recognise their value to contribute to improving global health, and to give nurses the opportunity for new energy and a new beginning. However, a number of factors seem to be conspiring to reduce nursing numbers. The introduction of students self-funding their initial education in England from September 2017 and the impact of the United Kingdom (UK) working to withdraw from the European Union, fewer candidates are applying to study nursing and increasing numbers of European nurses are returning to their home countries. Now more than ever, nurses need to be encouraged to work with partners around the world to promote more candidates into nursing and once qualified, retain them in the profession. Additionally, we need to encourage them to prepare themselves for leadership positions and to maximise their contribution in jobs where they will be valued and included in decision-making and policy (ICN 2018).

A similar campaign, the Global Advisory Panel on the future of Nursing and Midwifery (GAPFON) which recently reported in 2017 , aims to establish a voice and vision for the 
future of nursing and midwifery that intends to advance global health and at the same time, strengthen professional roles (Sigma Theta Tau International [Sigma] 2017). Sigma, the largest global professional nursing honor society and with its headquarters in the United States of America (USA) set up GAPFON in 2014, travelling to meet nurse leaders from across each of their seven geographic regions of the world to learn how nurses and midwives can "be a catalyst for global health partnerships and collaborations and help develop and influence policy and practice" (Sigma 2017, p2). Reporting in 2017, the project is now in the implementation phase to collaborate with educational partners to develop implementation plans, measurable outcomes and evaluation.

So, from these two global initiatives, nurses are seen as central to advancing global health and importantly significant investment is being made to support nurses to lead, learn and build this global movement. Education is central to these initiatives. Promoting nurses' confidence and competence to lead the future healthcare workforce is key. As previously acknowledged, Rosser (2017, 2015, 2014) and Rosser et al (2016) recognise the importance of education for leadership capability, for political participation and for the need to reach out through our global connections to empower individuals within the profession to identify ways to realise their potential and develop strong leadership to improve global health.

Words: 882

References

All-Party Parliamentary Group on Global Health (APPG) (2016) The Triple Impact: How developing nursing will improve health, promote gender equality and support economic growth. October, accessed at: http://www.appg-globalhealth.org.uk/ on 17.3.18

Institute of Medicine (2010) The Future of Nursing: Leading Change, Advancing Health. Accessed at; http://www.nationalacademies.org/hmd/Reports/2010/The-Future-of-NursingLeading-Change-Advancing-Health.aspx on 18.3.18

International Council of Nurses (2018) Nursing Now. Accessed at http://www.icn.ch/whatwe-do/Nusing-Now/ http://www.icn.ch/what-we-do/Nusing-Now/ on 18.3.18

Rosser, E. (2017) Encouraging political participation among the next generation. British Journal of Nursing, 26 (22), 1133.

Rosser, E. (2015) Creative Scholarship: the importance of global networks. British Journal of Nursing, 24 (14), 750.

Rosser, E., Scammell, J., Bevan, A. and Hundley, V. (2016) Strong leadership: the case for global connections. Journal of Clinical Nursing, 26, 946-955.

Rosser, E. (2014) What role can education play in developing leadership? British Journal of Nursing, 23(17), 54.

Sigma Theta Tau International (2017) The Global Advisory Panel on the Future of Nursing and Midwifery (GAPFON) Report. Accessed at

http://www.nursinglibrary.org/vhl/handle/10755/621599 on 17.3.18

\section{Professor Elizabeth Rosser \\ Acting Executive Dean \\ Bournemouth University \\ 18.3.18}

